\title{
Institutional factors affecting participation in national faculty development programs: a nation-wide investigation of medical schools
}

Do-Hwan Kim¹, Jinyoung Hwang ${ }^{2}$, Seunghee Lee ${ }^{1}$ and Jwa-Seop Shin ${ }^{1 *}$

\begin{abstract}
Background: Medical schools have used faculty development programs as an essential means to improve the instruction of faculty members. Thus far, however, participating in such programs has been largely voluntary for individuals even though a certain degree of participation is required to achieve practical effectiveness. In addition, the learning behaviors of faculty members are known to be influenced by organizational contexts such as a hidden curriculum. Therefore, this study explored the organizational characteristics of medical schools affecting attendance at faculty development programs.

Methods: Forty medical schools in South Korea were included in this study. In total, 1,667 faculty members attended the faculty development programs at the National Teacher Training Center for Health Personnel between 2007 and 2015. For independent variables, information on the basic characteristics and the educational states was collected from all the medical schools. Themes were identified from their educational goals and objectives by inductive content analysis.

Results: The number of nine-year cumulative attendees from medical schools ranged from 8 to 104. The basic characteristics of the medical schools had little influence on faculty development program attendance, while several themes in the educational goals and objectives, including "cooperation", "serving various societies", and "dealing with a changing future" showed a significant difference in participation. The number of full-time faculty showed a significant positive correlation when it was smaller than the median, and the proportion of alumni faculty showed a significant negative correlation when it was higher than $50 \%$.

Conclusions: This study adds to existing knowledge on factors affecting attendance at faculty development programs by identifying related institutional factors that influence attendance. While the variations depending on the basic characteristics were minimal, the organizational environment surrounding medical education significantly contributed to attendance. Addressing institutional as well as individual factors could contribute to improving participation by faculty members in faculty development programs.
\end{abstract}

Keywords: Faculty development program, Educational goals, National Teacher Training Center, Faculty members

\footnotetext{
* Correspondence: hismed1@snu.ac.kr

${ }^{1}$ Department of Medical Education, Seoul National University College of

Medicine, 103 Daehak-ro, Jongno-gu, Seoul 03080, Republic of Korea

Full list of author information is available at the end of the article
} 


\section{Background}

Medical schools have used faculty development programs (FDPs) as an essential means to manage and assist their faculty members to adapt to changes in internal and external environments [1,2]. While researchers have defined FDPs in a variety of ways, instructional development has steadily been the central focus of faculty development [3-5], and in practice, FDPs that prepare faculty members as medical teachers have been acknowledged as "imperative" for all medical schools [5].

However, the simple existence of FDPs does not ensure educational improvement by itself. In order for a FDP to facilitate teaching improvement at an organization, a certain degree of participation should be ensured [6]. From the perspective of individual faculty members, this is because attending FDPs is like "grammar school for teachers" to use a metaphor and an efficient way of obtaining at least the minimum required knowledge and skill needed to function as a medical teacher [6]. Second, for a medical school, having a critical mass of educators is vital because it helps to promote changes in the educational environment [7]. For instance, it has been argued that cumulative FDP attendees contribute by supporting critical periods such as curricular reform by forming a community of educators [8]. Third, for faculty developers, securing a certain level of participation is a practical issue because the operation of FDPs involves fixed expenses regardless of the number of paid attendees. Given that limited financial resources is one of the most common challenges faced by faculty developers [9], recruiting participants and charging registration fees for individuals or their affiliated organizations may help offset the expenses and mitigate the financial burden on faculty developers $[10,11]$.

Despite the importance of participating in FDPs, one problem regarding FDP attendance is that frequently the decision to attend is a voluntary one made by the individual rather than based on deficiencies in teaching skills or the need for improvement in the individual, which results in the case where "those who need faculty development the most attend the least" [12]. This case could be similar at the organizational level. It was reported that the manner in which institutions use FDPs is a manifestation of the institutions' inner faith in their workforce [2]. However, faith may not always correspond with their objective needs. More importantly, given that the learning behaviors of faculty members are affected by hidden curriculum comprised of various informal-tacit elements [13], the educational environment may exert a stronger influence than that of individual needs or interests in participating in FDPs.

For these reasons, it was suggested that studies on FDP participation should move beyond individual factors which basically rely upon volunteerism and delve into the "social determinants of participation" [14]. The significance of organizational context in faculty development was also underlined in a more recent article by O'Sullivan \& Irby, in which the authors called for process-oriented studies encompassing faculty development and workplace communities [15].

To the best of our knowledge, however, studies on FDP attendance are not only scarce but have also only focused on identifying factors mainly at the individual level $[6,16,17]$. One of the reasons for this could be in the case for which the majority of FDPs are institutional [18] where organizational factors of participation are difficult to isolate from individual factors due to their ubiquitous influence on participants. On the other hand, in South Korea, due to the existence of the National Teacher Training Center for Health Personnel (NTTC), the only representative institution specialized for faculty development, FDPs for medical schools have been done mainly at the national level which is relatively suitable for identifying institutional influences on participation. Since its inception, the NTTC has been provided with not only solid support from the domestic medical education community but also with external assistance from the WHO West Pacific Regional Office in 1970s and 1980s to strengthen the institution [19]. Furthermore, the unique geographical context of South Korea, where the area is the smallest among the top twenty countries with the highest number of medical schools [20], also has contributed to minimize the barrier to participation which originates from geographical distance.

Nonetheless, because medical schools generally do not have any mandatory requirement for NTTC FDP participation, the choice to attend FDPs was almost entirely decided by the medical schools and their members. Consequently, it resulted in considerable variation in the number of attendees among medical schools. Given this situation, the aim of this study was to examine the relationship between the attendance of NTTC FDPs by organizations and their characteristics, specifically for three types of factors - basic characteristics, educational goals and objectives, and educational states.

\section{Methods}

\section{Setting}

The NTTC, founded in 1975, is the leading institution for faculty development in South Korea. When it was first decided to set-up the NTTC at the Deans meeting for Korean Medical Schools, the primary purpose was to establish an institution specializing in the education and training of health professionals [21]. Based on the initial purpose of the NTTC, its programs have consistently been available to external domestic institutions despite the NTTC's status as an annex of Seoul National University College of Medicine (SNUCM). As 
the institution grew, a standard pattern for the NTTC FDPs was gradually established which can be characterized as (1) a workshop or a series of workshops (2) that are conducted at least once or twice a month (3) and are usually one or two days long for each program.

\section{Sample}

Participants in the NTTC FDPs between 2007 and 2015 were examined in this study. During this period, 4,195 faculty members participated in 158 workshops. Among them, we excluded 2,134 SNUCM faculty members because their participation was often compelled by an institutional promotion criteria or educational policy due to the exceptional relationship between the NTTC and SNUCM unlike the other medical schools. From the remaining 2,061 attendees, 394 faculty members who were from non-medical schools such as a school of dentistry or a school of nursing were also excluded. Finally, the collection and analysis of data were done for 1,667 faculty members from 40 medical schools in South Korea.

\section{Characteristics of medical schools Basic characteristics}

We chose to include fixed or relatively stable features of a medical school for the basic characteristics. In this category, we collected the following information - ownership (national/public vs private), location (capital area vs non-capital area), adoption of a graduate-entry program (GEP) (adopted vs not adopted), and founding year of the institution. When collecting the data, we referred to the relevant web pages at the official website for each school.

\section{Educational goals and objectives}

In 2015, three of the authors (DHK, JH, SL) identified 13 themes included in the educational goals and objectives of medical schools in South Korea with inductive content analysis [22]. Inductive content analysis is a qualitative research method used to create a conceptual system or categories which help to obtain a condensed description of textual data. This process is reductive and comprised of open coding, grouping, categorization, and abstraction [23, 24]. In the present study, the authors reviewed and revised the existing results of Kim et al. [22]. The themes were iteratively discussed until the differences were resolved; thus, finally, the medical schools were grouped according to their inclusion in each theme for the educational goals and objectives.

\section{Educational states}

To determine the independent variables included in this category, we examined and iteratively discussed items in the latest version of The Current State of Medical
Education (16 ${ }^{\text {th }}$ edition, exclusive for the Korea Association of Medical Colleges members only) published in 2012 and a white book published by the Research Institute for Healthcare Policy of Korean Medical Association in 2014 [25] as the principal sources of references. Similar to the basic characteristics, features that are essentially unchanging or stably maintained were mainly considered. Moreover, we gave consideration to whether documented information is integral and quantifiable. Finally, the data collected from each medical school included the size of a class, the established year of the department of medical education (DME), the length of the formal curriculum, and the number of full-time faculty. Regarding the faculty members, the proportion of alumni faculty, which was defined as faculty members currently employed by their alma mater medical school, was calculated as well.

\section{Statistical analysis}

In this study, independent variables were various characteristics of medical schools and dependent variable was the number of cumulative attendees from 2007 to 2015 . However, contrast with basic characteristics or educational states which are relatively stable, medical schools occasionally review and revise their educational objectives to meet changing internal and external needs. Therefore, additional dependent variable that focuses on more recent data, the number of cumulative attendees from 2013 to 2015, was also analyzed as dependent variable to confirm the consistency of the findings. Lastly, we investigated if the number of participants in year $\mathrm{N}$ has correlation with that in year $\mathrm{N}-1$ and cumulative participants from 2007 to year $\mathrm{N}-1$.

Although this study to reach a near nation-wide investigation that embraces all medical schools only except SNUCM, the sample size was inevitably restricted by their total number. Nevertheless, because parametric statistics is highly robust even when the assumptions with regard to sample size or normality are violated [26], independent sample $t$-test or Pearson correlation was used when independent variables were dichotomous or continuous, respectively. $P$-values less than 0.05 were considered statistically significant.

\section{Results}

\section{Characteristics of medical schools}

Since 1998, there have been a total of 41 medical schools including SNUCM in South Korea, and all of the medical schools had at least eight faculty members who participated in the NTTC FDPs between 2007 and 2015 (Table 1). The average number of attendees per medical school was 42.1, and the median was 37 . Among the 40 medical schools, nine were national/public; fourteen 
Table 1 Descriptive statistics for 40 medical schools in South Korea

\begin{tabular}{|c|c|c|c|}
\hline Categories & & & $\begin{array}{l}\text { Total medical schools } \\
(100 \%, N=40)^{\mathrm{a}}\end{array}$ \\
\hline FDP participants & Number of cumulative participants from 2007 to 2015 & & $42.1 \pm 27.7$ (range: $8-104)$ \\
\hline \multirow[t]{7}{*}{ Basic Characteristics } & \multirow[t]{2}{*}{ Ownership } & National/Public & $22.5 \%(9)$ \\
\hline & & Private & $77.5 \%(31)$ \\
\hline & \multirow[t]{2}{*}{ Geographical position } & Capital area & $35.0 \%(14)$ \\
\hline & & Non-capital area & $65.0 \%(26)$ \\
\hline & \multirow[t]{2}{*}{ Graduate-entry program } & $\begin{array}{l}\text { Adopted } \\
\text { (partly or fully) }\end{array}$ & $65.0 \%(26)$ \\
\hline & & Not adopted & $35.0 \%(14)$ \\
\hline & Founding year of medical school & & $1975.8 \pm 22.6$ (range: $1885-1998)$ \\
\hline Educational goals and objectives & Number of themes included (Maximum: 13) & & $8.3 \pm 2.07$ (range: $4-13$ ) \\
\hline \multirow[t]{6}{*}{ Educational states } & Size of a class (n) & & $73.1 \pm 29.8$ (range: $40-125)$ \\
\hline & \multirow[t]{2}{*}{ Established year of $\mathrm{DME}^{\mathrm{b}}$} & Not established & n.a \\
\hline & & yet Established & $2004 \pm 4.53$ (range: 1995-2012) \\
\hline & Length of formal curriculum (weeks) & & $152.1 \pm 12.1$ (range: $120-183.6)$ \\
\hline & Number of full-time faculty $(n)$ & & $260.0 \pm 175.0$ (range: $89-863$ ) \\
\hline & $\begin{array}{l}\text { Percentage of full-time faculty who graduated } \\
\text { from their current affiliated medical school (i.e., alumni faculty) }\end{array}$ & & $41.4 \pm 32.2$ (range: $0.18-95.0$ ) \\
\hline
\end{tabular}

FDP faculty development program, DME department of medical education

${ }^{a}$ Among 41 medical schools in South Korea, Seoul National University College of Medicine, where NTTC is located, was excluded in the statistics; ${ }^{b}$ This excludes any administrative office related to medical education, such as "Office of Medical Education". In total, among 40 medical schools, 26 had DME or similar entity

were located in the capital area, and twenty-six adopted a graduate-entry program. The years for establishment ranged from 1885 to 1998 , and the median was 1981 . Among the 13 themes that were identified through the inductive content analysis, each medical school had 8.3 themes on average in its educational goals and objectives. Approximately two-thirds of the medical schools had DMEs with a median year of establishment of 2004. The medical schools admitted on average 73.1 students per year and had 260 full-time faculty members, among which $41.4 \%$ were alumni faculty.

\section{Influence of basic characteristics}

We examined the variation in the 9-year cumulative number of NTTC FDP attendees of medical schools depending on their basic characteristics (Table 2). The numbers of attendees, however, showed no statistically significant difference irrespective of a medical school's ownership, geographical position, adoption of a graduate-entry program, and founding year.

\section{Influence of themes in the educational goals and objectives}

To evaluate the effect of the educational mission, the FDP attendance of medical schools was compared according to whether a certain theme was contained in the educational goals and objectives (Table 3). A statistically significant or near-significant difference in the number of attendees was observed in three of the thirteen themes. First, medical schools that highlighted "cooperation" in education had a

Table 2 The influence of various basic characteristics of medical schools

\begin{tabular}{|c|c|c|c|}
\hline \multirow[t]{2}{*}{ Variable } & & \multicolumn{2}{|c|}{ Cumulative participants from 2007 to $2015^{a}$} \\
\hline & & Values & $p$-value \\
\hline \multirow[t]{2}{*}{ Ownership $^{a}$} & National/Public & $41.77 \pm 27.89$ & 0.884 \\
\hline & Private & $43.33 \pm 28.39$ & \\
\hline \multirow[t]{2}{*}{ Geographical position a,b } & Capital area & $41.38 \pm 26.85$ & 0.821 \\
\hline & Non-capital area & $43.5 \pm 30.06$ & \\
\hline \multirow[t]{2}{*}{ Graduate-entry program ${ }^{\mathrm{a}, \mathrm{b}}$} & Adopted (partly or fully) & $44.57 \pm 30.96$ & 0.687 \\
\hline & Not adopted & $40.80 \pm 26.24$ & \\
\hline Founding year of medical school ${ }^{c}$ & Correlation & 0.049 & 0.762 \\
\hline
\end{tabular}


Table 3 Themes in the educational goals and the number of attendees

\begin{tabular}{|c|c|c|c|c|c|c|}
\hline & & & $\begin{array}{l}\text { Cumulative pa } \\
\text { to } 2015\end{array}$ & ts from 2007 & $\begin{array}{l}\text { Cumulative p } \\
\text { to } 2015\end{array}$ & ts from 2013 \\
\hline & & & Values & $p$-value & Values & $p$-value \\
\hline Total numb & of themes included & Correlation $^{\mathrm{a}}$ & -0.223 & 0.167 & -0.264 & 0.100 \\
\hline Themes ${ }^{b, c}$ & Medical expertise $^{d}$ & & n.a. & & n.a. & \\
\hline & Professionalism & Not included (38) & $67.66 \pm 43.82$ & 0.097 & $26.33 \pm 25.50$ & 0.416 \\
\hline & & Included (2) & $40.05 \pm 25.74$ & & $11.35 \pm 9.45$ & \\
\hline & Serving various societies ${ }^{\mathrm{e}}$ & Not included (36) & $77.75 \pm 41.24$ & 0.005 & $28.0 \pm 14.44$ & 0.003 \\
\hline & & Included (4) & $38.16 \pm 23.34$ & & $10.75 \pm 9.91$ & \\
\hline & Self-management and development & Not included (35) & $48.5 \pm 35.06$ & 0.547 & $12.5 \pm 10.54$ & 0.995 \\
\hline & & Included (5) & $41 \pm 26.61$ & & $12.47 \pm 11.78$ & \\
\hline & Founding philosophy & Not included (28) & $53.76 \pm 25.60$ & 0.064 & $15.92 \pm 16.37$ & 0.304 \\
\hline & & Included (12) & $36.51 \pm 27.26$ & & $10.81 \pm 8.067$ & \\
\hline & Research ability & Not included (28) & $49.92 \pm 30.82$ & 0.220 & $15.15 \pm 11.75$ & 0.312 \\
\hline & & Included (12) & $38.37 \pm 25.75$ & & $11.18 \pm 11.33$ & \\
\hline & Cooperation & Not included (26) & $31.28 \pm 17.37$ & 0.034 & $8.64 \pm 6.70$ & 0.066 \\
\hline & & Included (14) & $47.96 \pm 30.56$ & & $14.53 \pm 13.02$ & \\
\hline & Leadership & Not included (24) & $44.37 \pm 26.41$ & 0.680 & $11.31 \pm 11.17$ & 0.607 \\
\hline & & Included (16) & $40.62 \pm 28.90$ & & $13.25 \pm 11.84$ & \\
\hline & Dealing with a changing future & Not included (20) & $49.71 \pm 31.27$ & 0.063 & $16.28 \pm 13.44$ & 0.023 \\
\hline & & Included (20) & $33.73 \pm 20.68$ & & $8.26 \pm 6.99$ & \\
\hline & Respect for life & Not included (20) & $40.75 \pm 27.73$ & 0.758 & $14.05 \pm 13.40$ & 0.392 \\
\hline & & Included (20) & $43.5 \pm 28.21$ & & $10.9 \pm 9.244$ & \\
\hline & Creativity & Not included (20) & $40.95 \pm 24.37$ & 0.782 & $11.09 \pm 9.787$ & 0.431 \\
\hline & & Included (20) & $43.42 \pm 31.51$ & & $14 \pm 13.20$ & \\
\hline & Problem-solving ability & Not included (19) & $39.33 \pm 25.15$ & 0.509 & $13.90 \pm 11.52$ & 0.415 \\
\hline & & Included (21) & $45.21 \pm 30.56$ & & $10.89 \pm 11.52$ & \\
\hline & Ability of education & Not included (6) & $43.82 \pm 28.54$ & 0.309 & $13.14 \pm 11.97$ & 0.337 \\
\hline & & Included (34) & $30.2 \pm 17.99$ & & $7.8 \pm 5.890$ & \\
\hline
\end{tabular}

n.a. not available

${ }^{\mathrm{a}}$ Pearson correlation; ${ }^{\mathrm{b}}$ independent samplet-test; ${ }^{\mathrm{c}}$ Mean $\pm \mathrm{SD} ;{ }^{\mathrm{d}}$ This theme was included in educational goal of 39 out of 40 medical schools; ${ }^{\mathrm{e}}$ This includes local, regional, national, and international societies

higher attendance for both dependent variables compared to those who did not. In contrast, when "serving various societies" or "dealing with a changing future" was included, there were significantly less attendees than when the theme was not included.

\section{Influence of educational states}

Among factors related to medical education, the number of cumulative attendees was not significantly correlated with either the size of a class or the length of the formal curriculum (Table 4). Whether a medical school has a DME did not show any significant influence; however, when an analysis was conducted with the 26 medical schools that do have a DME, DMEs that were established more recently had more faculty members attending the NTTC FDPs.
With respect to faculty members, both the number of full-time faculty and the proportion of alumni faculty did not show any significant correlation with FDP attendance overall. Nevertheless, a different result emerged when we restricted the range of the independent variables. First, the number of full-time faculty showed a significant positive correlation only when the number of full-time faculty was smaller than the median number of full-time faculty, which was 189 . Second, the proportion of alumni faculty had a significant negative correlation only when the proportion of alumni faculty was higher than $50 \%$.

\section{Correlation between the number of attendees}

The correlation between the number of $\mathrm{N}^{\text {th }}$ year attendees and $\mathrm{N}-1^{\text {th }}$ year attendees was significant with a 
Table 4 The influence of educational states

\begin{tabular}{|c|c|c|c|c|}
\hline \multirow[t]{2}{*}{ Variable } & & & \multicolumn{2}{|c|}{ Cumulative participants from 2007 to 2015} \\
\hline & & & Values & $p$-value \\
\hline Size of a class ${ }^{a}$ & & & 0.142 & 0.382 \\
\hline Length of formal curriculum (weeks) ${ }^{a}$ & & & -0.189 & 0.248 \\
\hline \multirow[t]{3}{*}{ DME } & \multirow[t]{2}{*}{ Establishment $^{\mathrm{b}}$} & Not established yet & $38.64 \pm 30.32$ & $0.566^{\mathrm{c}}$ \\
\hline & & Established & $44.0 \pm 26.53$ & \\
\hline & Established year of $\mathrm{DME}^{\mathrm{a}}$ & & 0.397 & 0.045 \\
\hline \multirow[t]{3}{*}{ Number of full-time faculty ${ }^{a}$} & Total number of full-time faculty & & 0.167 & 0.302 \\
\hline & Total faculty $<$ median & & 0.460 & 0.041 \\
\hline & Total faculty $\geq$ median & & 0.267 & 0.256 \\
\hline \multirow{3}{*}{$\begin{array}{l}\text { Proportion of full-time faculty who graduated } \\
\text { from their own medical school }{ }^{\mathrm{a}}\end{array}$} & Proportion of alumni faculty & & 0.008 & 0.961 \\
\hline & Proportion $<50 \%$ & & 0.165 & 0.476 \\
\hline & Proportion $\geq 50 \%$ & & -0.670 & 0.006 \\
\hline
\end{tabular}

DME department of medical education

${ }^{\text {a }}$ Pearson correlation with cumulative participants from 2007 to $2015 ;{ }^{b}$ Mean $\pm S D{ }^{c}$ independent sample $t$-test

strength that ranged from 0.360 to 0.808 except for three of the eight cases (Table 5). Likewise, the cumulative total of the $\mathrm{N}-1^{\text {th }}$ year was also positively correlated with the number of attendees of the $\mathrm{N}^{\text {th }}$ year except for three cases. In this case, the strength of the correlation ranged from 0.390 to 0.706 .

\section{Discussion}

In this study, we investigated the institutional factors affecting participation in national faculty development programs. The results indicate that while the influence of the basic characteristics of medical schools is insignificant, several factors regarding educational missions, including the established year of a DME and the quantitative and qualitative features of faculty members, significantly affected the FDP attendance of medical schools. Moreover, not only the cumulative attendance but also the number of attendees in a specific year predicted the number of attendees for the following year.

The first finding of this study is that four factors, which we categorized as basic characteristics, have little impact on the number of FDP attendees. This might seem unusual because the features of medical schools including ownership [27], geographic position [28], type of M.D. granting program [29], history and tradition [30] are often reflected in the outcome or orientation that institutions pursue by means of education. However, taking into account the history of the growth of medical schools in South Korea over the last few decades, the results are rather reasonable. For instance, the rapid expansion of medical schools, which took place over a relatively short period, has resulted in an immature social agreement on the accountability of medical schools [31]. This, in turn, has brought about the current circumstance for which it is hardly possible to differentiate between national/public and private medical schools in terms of their educational missions [22] as well as their actual curriculum [32]. Another reason could be procedural weaknesses in the implementation of major policies such as establishing new medical schools or introducing GEPs. Researchers have pointed out that there was frequent interference from political and economic interests instead of using evidence-based research on education in the process for adopting those policies [33]. Furthermore, mutual understanding between the government and medical schools with regard to the background and aims of the policies was inadequate also.

However, compared to the basic characteristics, elements that are more closely connected to medical education showed an association with FDP attendance. First, the number of FDP attendees was higher for medical schools that have "cooperation" in their educational

Table 5 Correlations between the number of attendees

\begin{tabular}{llllllllll}
\hline & Number & 2008 & 2009 & 2010 & 2011 & 2012 & 2013 & 2014 & 2015 \\
\hline $\mathrm{N}-1^{\text {th }}$ year $-\mathrm{N}^{\text {th }}$ year & Correlation & 0.646 & 0.808 & 0.360 & 0.221 & 0.216 & 0.020 & 0.614 & 0.509 \\
& $p$-value & 0.000 & 0.000 & 0.023 & 0.170 & 0.181 & 0.902 & 0.000 & 0.001 \\
Cumulative total of $\mathrm{N}-1^{\text {th }}$ year $-\mathrm{N}^{\text {th }}$ year & Correlation & 0.646 & 0.706 & 0.289 & 0.236 & 0.178 & 0.437 & 0.390 & 0.509 \\
& $p$-value & 0.000 & 0.000 & 0.071 & 0.143 & 0.273 & 0.005 & 0.013 & 0.001 \\
\hline
\end{tabular}

${ }^{\mathrm{a}}$ Pearson correlation 
goals and objectives. It has been argued that FDPs increase cooperative interactions among faculty members [14]. Moreover, given the large numbers of faculty members involved, integration of curriculums by the joint contribution and harmony of teachers is necessary especially in this era of competency-based medical education [34, 35]. Namely, medical education is a 'team sport' whose excellence is more likely to be achieved through cooperative effort for shared values rather than through a mere collection of independent individuals [36]. Therefore, medical schools might utilize FDPs more actively if they appreciate "cooperation" as a primary educational goal.

In contrast, there were fewer FDP attendees when medical schools emphasized "serving various societies" or "dealing with a changing future". These objectives are more focused on external stakeholders or extrinsic stimuli compared to "cooperation" which is more intrinsic. It is natural for a medical school to properly adjust oneself to the ever-changing needs of the external environment [37] given the imposed expectation to fulfill the social contract with the public [38]. However, considering the limited available resources of faculty members and medical schools [39], the negative association of the extrinsic educational objectives on FDP attendance implies that a delicate balance is required when fulfilling the needs of external stakeholders and developing the internal capacity of faculty members concurrently.

In addition to educational goals and objectives, several features relevant to the educational environment were also correlated with FDP attendance. Unlike the founding year of the medical schools, the year when a DME was established had a significant correlation with the cumulative number of attendees. In other words, FDP attendance was significantly decreased as the chronological age of a DME increased. It could be primarily explained by the organizational capability for running FDPs. Given that one of the major roles of a DME is to educate and train medical teachers [5], a DME with a longer history may have accumulated enough experience and resources so that it could independently perform the role without relying on the NTTC FDPs while a newer DME requires more support. On the other hand, however, it is also worth considering that established traditions often impede achieving meaningful changes in an organization by hindering it from learning new things and reinventing itself [40]. Briefly, the negative effect of the increasing age of a DME exerted on the NTTC FDP attendance could be attributed to either the sufficient capacity of a long-standing DME or its liability in maintaining the status quo which needs further investigation.

Regarding the number of faculty members, it would be intuitive to expect that the number of FDP attendees will keep increasing as the number of faculty members increases, if assuming that only individual factors affect participation. However, our findings show that the relationship was valid only for those medical schools whose number of faculty members was under the median number of faculty members. This implies the possible existence of influences stemming from size-related factors which is consistent with previous studies which indicated that the large size of an organization tends to negatively affect implementing institution-wide behavioral changes [41, 42]. For medical schools, it becomes more complicated due to their three connected missions - education, research, and clinical service - which are interdependent but sometimes conflict with each other [43]. This tension may prevent medical schools from increasing investment in education in order to pursue the two other missions simultaneously. In addition, the fact that the largest school has ten times as many faculty members as that of the smallest one ( 89 vs 863 ), which is a far greater difference than the difference in the number of entering students (40 vs 125), might also cause the FDP attendance of medical schools to plateau.

The composition of the faculty members was also important in FDP participation. First, the number of attendees showed a significant negative correlation with the proportion of alumni faculty when it was above $50 \%$. A problem with the so-called "pure-bloodism" could be the homogenization of learning experiences among faculty members because their experiences as learners are the primary factor that shapes their teaching style [44]. In such medical schools, it is easier for junior faculty members to "inherit" the teaching style of senior faculty members through the medium of learning experiences which can become prevalent in organizational practices. In relation to FDP participation, this homogenization is particularly challenging for organizations as well as faculty developers, because it could promote group conformity which often results in faculty members failing to recognize the necessity of improving their current practices, or even worse, remaining silent even when they recognize that corrective action is necessary [45].

Second, our data show that the number of FDP attendees in a certain year significantly predicted the number of FDP attendees in the next year. The exceptions were for the period when the NTTC concentrated its resources on internal capacity building of the SNUCM faculty at the expense of national-wide programs. Of note is that those correlations were repeatedly observed over the years implying that a medical school's inclination for FDP attendance is a relatively stable trait. Researchers have reported that peer support and a feeling of connectedness with a community of educators are crucial for the development of faculty members as teachers [46]. In this aspect, one of the reasons for a constantly low 
FDP attendance could be the scattered distribution of the scarce FDP attendees which, in turn, hinders the formation of a community of peers that motivates selfdevelopment as a teacher. This is consistent with previous findings that emphasized a critical mass of educators is a key factor in making behavioral changes $[7,47]$.

\section{Implications for faculty developers}

One of the findings, seemingly obvious yet important, is that there is great variation between medical schools in their NTTC FDP attendance. Moreover, it seems clear that there are medical schools with low attendance, especially showing a continuous trend for low attendance. Systematic reviews, which used the Kirkpatrick model for the evaluation, have already proven that FDPs have substantial beneficial effects over all levels [14, 48]. However, one thing, which should not be overlooked, is that even the level 1 outcome, i.e., satisfaction, is unable to take place unless participation is assumed. Similarly, Marbach-Ad et al. have suggested a five-level model to evaluate teaching and learning programs, which included "participation" on its first level to understand who participates and why individuals participate followed by "satisfaction" on the next level [49]. It is therefore necessary for faculty developers to pay more attention to participation as "level 0 " of the evaluation, especially for those with persistent low attendance.

To promote the participation of faculty members, the first thing we need to understand is what encourages them to participate in FDPs. Although researchers have already identified various reasons for participation at the individual level $[6,16,17]$, our results show that institutional factors also affect FDP participation. The fact that the number of FDP attendees no longer proportionally increases once the size of the faculty reaches a certain point also implies that institutional factors are operating in addition to individual ones. Therefore, when faculty developers seek more medical teachers to take part in FDPs, addressing personal factors might not be sufficient, and institutional contexts affecting FDP attendance must also be taken into consideration.

Lastly, another recent trend that makes institutional factors more important is the expansion of the scope of FDPs from institutional to national or even international [18]. Similar to individuals having diverse reasons for attending FDPs, each medical school would have different types and combinations of institutional factors, i.e., a hidden curriculum that influences faculty behaviors. Therefore, as Steinert pointed out, faculty developers who want to broaden their audience would need to use targeted marketing strategies depending on their target institutions [50]. For example, when selecting new targets for promoting their programs, medical schools with factors that contribute positively to FDP participation could be considered as a priority for marketing efficiency, such as institutions that have recently established a DME, are not too large, or emphasize "cooperation" in their educational goals. Meanwhile, for existing participating institutions whose trend for attendance is already known, identifying the institutional factors related to education as well as examining the characteristics of previous attendees would be required as baseline data to refine the marketing strategies for a specific institution.

\section{Limitations}

The first limitation of this study is that it was conducted based on data from a single institution, the NTTC, which aims to serve medical schools across South Korea. Thus, the socio-historical context of the institution or nation could have been reflected in the findings. However, the exceptional context consisting of a single national institution specialized for faculty development also offered a favorable setting for a nation-wide study. Second, values collected for some of the independent variables are not permanent because medical schools are constantly changing to adapt to changes in the environment. However, after the implementation of the GEP in 2005, South Korea has maintained a relatively stable medical education environment. Additionally, we used 9-year cumulative attendees as the dependent variable so that the effect due to the year-to-year variation remains minimal. Third, the causal inferences from our correlational relationships could be limited, especially when factors such as organizational capability for running FDPs mediate the relationship. In addition, some institutional factors might influence only specific types of FDPs. Even though it could not be examined due to the difficulties in categorizing NTTC FDPs that often cover multiple topics in a single program, in further studies, it would be worth exploring how the effect of institutional factors on participation varies by the types of programs.

\section{Conclusions}

In this study, we investigated factors at medical schools that influence participation in FDPs. Although medical schools did not show any variations based on their basic characteristics, the organizational environment surrounding medical education, such as the educational missions, the history of a DME, and the qualitative and quantitative features of faculty members, had a significant contribution on FDP attendance. Although the context of the NTTC and South Korea might be a limitation, it seems evident that faculty developers should not ignore institutional factors to promote medical faculty buy-in. Further research is needed to reveal additional institutional factors as well as the mechanisms underlying them. 


\section{Abbreviations}

DME: Department of medical education; FDP: Faculty development program; GEP: Graduate-entry program; NTTC: National Teacher Training Center for Health Personnel; SNUCM: Seoul National University College of Medicine; UEP: Undergraduate-entry program

\section{Acknowledgements}

The authors would like to express gratitude to Prof. Young-il Hwang for providing helpful comments on this article.

\section{Funding}

This work was supported by the Education and Research Encouragement Fund of Seoul National University Hospital (2017)

\section{Availability of data and materials}

The datasets analyzed during the current study are available from the corresponding author for reasonable requests.

\section{Authors' contributions}

DHK and JSS conceived the initial design of the study and drafted the manuscript. DHK, JH and SL contributed to the analysis of the qualitative data. DHK collected and analyzed the quantitative data. DHK and JH contributed to the interpretation of the data. All authors read, critically reviewed, and approved the final manuscript.

\section{Competing interests}

The authors declare that they have no competing interests.

\section{Consent for publication}

Not applicable.

\section{Ethics approval and consent to participate}

Not applicable. Institutional Review Board of SNUCM verified that ethics approval is not needed because the subjects of this study were medical schools not humans.

\section{Author details}

${ }^{1}$ Department of Medical Education, Seoul National University College of Medicine, 103 Daehak-ro, Jongno-gu, Seoul 03080, Republic of Korea. 2Department of Educational Psychology, The University of Texas at Austin, 1 University Station, MS/D5800, Austin, TX 78712, USA.

\section{Received: 4 October 2016 Accepted: 20 February 2017} Published online: 28 February 2017

\section{References}

1. Centra JA. Types of faculty-development programs. J High Educ. 1978;49(2): $151-62$

2. Bligh J. Faculty development. Med Educ. 2005;39(2):120-1.

3. Sheets KJ, Schwenk TL. Faculty development for family medicine educators: an agenda for future activities. Teach Learn Med. 1990;2(3):141-8.

4. Wilkerson L, Irby DM. Strategies for improving teaching practices: a comprehensive approach to faculty development. Acad Med. 1998:73(4): 387-96

5. McLean M, Cilliers F, Van Wyk JM. Faculty development: yesterday, today and tomorrow. Med Teach. 2008;30(6):555-84.

6. Steinert Y, McLeod PJ, Boillat M, Meterissian S, Elizov M, Macdonald ME Faculty development: a 'field of dreams'? Med Educ. 2009;43(1):42-9.

7. Plack MM, Goldman EF, Wesner M, Manikoth N, Haywood Y. How learning transfers: a study of how graduates of a faculty education fellowship influenced the behaviors and practices of their peers and organizations. Acad Med. 2015;90(3):372-8.

8. Haramati A. Educating the educators: a key to curricular integration. Acad Med. 2015:90(2):133-5.

9. Dent J, Harden RM. A practical guide for medical teachers. 3rd ed. Philadelphia: Elsevier Churchill Livingstone; 2013.

10. Magnotto JN, Stout BR. Faculty workshops. In: McLeod SH, Soven M, editors. Writing across the curriculum: a guide to developing programs. Newbury Park: Sage Publications; 1992. p. 32-46.
11. Skeff KM, Stratos GA, Bergen MR, Albright CL, Berman J, Farquhar JW, et al. The Stanford faculty development program: a dissemination approach to faculty development for medical teachers. Teach Learn Med. 1992;4(3):180-7.

12. Steinert $Y$. Perspectives on faculty development: aiming for $6 / 6$ by 2020 . Perspect Med Educ. 2012;1(1):31-42.

13. Hafler JP, Ownby AR, Thompson BM, Fasser CE, Grigsby K, Haidet P, et al. Decoding the learning environment of medical education: a hidden curriculum perspective for faculty development. Acad Med. 2011;86(4):440-4.

14. Steinert Y, Mann K, Centeno A, Dolmans D, Spencer J, Gelula M, et al. A systematic review of faculty development initiatives designed to improve teaching effectiveness in medical education: BEME Guide No. 8. Med Teach. 2006;28(6):497-526.

15. O'Sullivan PS, Irby DM. Reframing research on faculty development. Acad Med. 2011:86(4):421-8

16. Skeff KM, Stratos GA, Mygdal W, DeWitt TA, Manfred L, Quirk M, et al. Faculty development. A resource for clinical teachers. J Gen Intern Med. 1997;12 Suppl 2:S56-63.

17. Steinert Y, Macdonald ME, Boillat M, Elizov M, Meterissian S, Razack S, et al. Faculty development: if you build it, they will come. Med Educ. 2010:44(9):900-7.

18. Leslie K, Baker L, Egan-Lee E, Esdaile M, Reeves S. Advancing faculty development in medical education: a systematic review. Acad Med. 2013; 88(7):1038-45.

19. Regional Office for the Western Pacific. Health Manpower Development: Medium-term programme. World Health Organization. 1977. http://iris.wpro. who.int/bitstream/handle/10665.1/9295/WPR_RC028_06_ HealthManpowerDevt_1977_en.pdf. Accessed 13 Sept 2016.

20. Duvivier RJ, Boulet JR, Opalek A, van Zanten M, Norcini J. Overview of the world's medical schools: an update. Med Educ. 2014:48(9):860-9.

21. Baik SH. A historical perspective of the korean society of medical education. Korean J Med Educ. 2012:24(1):3-6.

22. Kim DH, Kim EJ, Hwang J, Shin JS, Lee S. What is the current orientation of undergraduate medical education in Korea? Korean J Med Educ. 2015;27(2): 87-98.

23. Elo S, Kyngas $H$. The qualitative content analysis process. J Adv Nurs. 2008; 62(1):107-15.

24. Graneheim UH, Lundman B. Qualitative content analysis in nursing research: concepts, procedures and measures to achieve trustworthiness. Nurse Educ Today. 2004:24(2):105-12.

25. Korean Medical Association. A study on the present state of medical education in Korea: the white book. Seoul: Research Institute for Healthcare Policy; 2014.

26. Norman G. Likert scales, levels of measurement and the "laws" of statistics. Adv Health Sci Educ Theory Pract. 2010;15(5):625-32.

27. Grbic D, Hafferty FW, Hafferty PK. Medical school mission statements as reflections of institutional identity and educational purpose: a network text analysis. Acad Med. 2013;88(6):852-60.

28. Rosenblatt RA, Whitcomb ME, Cullen TJ, Lishner DM, Hart LG. Which medical schools produce rural physicians? JAMA. 1992;268(12):1559-65.

29. Elliott SL, Epstein J. Selecting the future doctors: the role of graduate medical programmes. Intern Med J. 2005;35(3):174-7.

30. Lewkonia RM. The missions of medical schools: the pursuit of health in the service of society. BMC Med Educ. 2001;1:4.

31. Ahn D. The future roles of Korean doctors: cultivating well-rounded doctors. Korean Med Educ Rev. 2014;16:119-25.

32. Chung CW. Current situation of medical professionalism education in Korean medical schools. Korean J Med Educ. 2004;16(3):259-67.

33. Shin JS. A review on the courses of the introduction of postbaccalaureate basic medical education system in Korea. Korean J Med Educ. 2006;18(2):121-32.

34. Harden RM. The integration ladder: a tool for curriculum planning and evaluation. Med Educ. 2000;34(7):551-7

35. Chen $\mathrm{HC}$, van den Broek WE, ten Cate O. The case for use of entrustable professional activities in undergraduate medical education. Acad Med. 2015; 90(4):431-6.

36. Steinert Y. Making It All Happen: Faculty Development for Busy Teachers. Learning and Teaching in Medicine. 2010:73.

37. Grigsby RK, Hefner DS, Souba WW, Kirch DG. The future-oriented department chair. Acad Med. 2004:79(6):571-7.

38. McCurdy L, Goode LD, Inui TS, Daugherty Jr RM, Wilson DE, Wallace AG, et al. Fulfilling the social contract between medical schools and the public Acad Med. 1997;72(12):1063-70. 
39. Morahan PS, Fleetwood J. The double helix of activity and scholarship: building a medical education career with limited resources. Med Educ 2008;42(1):34-44

40. Lane IF. Change in higher education: understanding and responding to individual and organizational resistance. J Vet Med Educ. 2007;34(2):85-92.

41. Bland CJ, Starnaman S, Wersal L, Moorehead-Rosenberg L, Zonia S, Henry R. Curricular change in medical schools: how to succeed. Acad Med. 2000; 75(6):575-94.

42. Bloom SW. The medical school as a social organization: the sources of resistance to change. Med Educ. 1989;23(3):228-41.

43. Ramsey PG, Miller ED. A single mission for academic medicine: improving health. JAMA. 2009;301(14):1475-6.

44. MacDougall J, Drummond MJ. The development of medical teachers: an enquiry into the learning histories of 10 experienced medical teachers. Med Educ. 2005;39(12):1213-20.

45. Beran TN, Kaba A, Caird J, McLaughlin K. The good and bad of group conformity: a call for a new programme of research in medical education. Med Educ. 2014;48(9):851-9.

46. Lown BA, Newman LR, Hatem CJ. The personal and professional impact of a fellowship in medical education. Acad Med. 2009;84(8):1089-97.

47. Gruppen LD, Simpson D, Searle NS, Robins L, Irby DM, Mullan PB. Educational fellowship programs: common themes and overarching issues. Acad Med. 2006;81(11):990-4

48. Steinert Y, Naismith L, Mann K. Faculty development initiatives designed to promote leadership in medical education. A BEME systematic review: BEME Guide No. 19. Med Teach. 2012:34(6):483-503.

49. Marbach-Ad G, Egan L, Thompson KV. A discipline-based teaching and learning center: a model for professional development. New York: Springer; 2015.

50. Steinert $Y$. Developing medical educators: A journey, not a destination. Understanding medical education: Evidence, theory and practice. 2010:403-18.

\section{Submit your next manuscript to BioMed Central and we will help you at every step:}

- We accept pre-submission inquiries

- Our selector tool helps you to find the most relevant journal

- We provide round the clock customer support

- Convenient online submission

- Thorough peer review

- Inclusion in PubMed and all major indexing services

- Maximum visibility for your research

Submit your manuscript at www.biomedcentral.com/submit 